\title{
NOTA SOBRE A CONTROVÉRSIA FRASER-HONNETH INFORMADA PELO CENÁRIO BRASILEIRO
}

Celi Regina Jardim Pinto

O presente artigo examinará a controvérsia Fraser-Honneth (2003) a propósito do binômio distribuição-reconhecimento e do estatuto teórico do conceito de reconhecimento, com o objetivo primeiro de discutir a aplicabilidade das propostas para casos como o brasileiro: até onde Honneth e Fraser oferecem instrumentos para análise do Brasil, até onde suas teorias têm valor normativo para o país?

A proposta de análise que estou fazendo neste texto buscou exemplo na própria Nancy Fraser, em um momento bastante distinto de sua produção, quando a autora classifica de falsa antítese a polêmica entre Buttler e Benhabib sobre a postura emancipatória do feminismo vis-à-vis à modernidade e à pós-modernidade. São de Fraser as palavras:

"Nestes casos, proporei uma formulação alternativa, mais modesta e defensável que evita generalizar a falsa antítese entre a Teoria Crítica e o pós-estruturalismo. Meu objetivo maior é preservar os melhores elementos de cada paradigma, e daí ajudar a preparar o terreno para sua integração na teorização feminista” (1995, p. 60) ${ }^{1}$.

\footnotetext{
${ }^{1}$ Estas e todas as traduções dos autores citados neste texto são minhas.
} 
Parafraseando Fraser, afirmaria que existe uma falsa antítese entre ela e Honneth, e que reter os melhores elementos de cada teoria é altamente positivo, tendo em vista uma teoria normativa da justiça, principalmente, com olhos voltados para a questão brasileira.

A propósito da polêmica, listarei seis pontos que aqui funcionarão como hipóteses contrárias à incompatibilidade das teorias, preservando, entretanto, seus elementos diferenciais fundamentais:

1. A distribuição não pode ser reduzida ao reconhecimento, sob pena de anulá-la como questão de justiça.

2. Reconhecimento é um conceito polissêmico e sua redução a uma definição exclusiva retira tanto seu valor heurístico para a teoria social, como sua potencialidade na luta por justiça.

3. O reconhecimento como auto-reconhecimento(estima) encontrado na tese de Honneth e o reconhecimento como status, encontrada na tese de Fraser, não se excluem, mas fazem parte de momentos distintos de elaboração teórica e da luta política, que em algumas circunstâncias podem aparecer como complementares.

4. O reconhecimento como política pública e como política de Estado independe do auto-reconhecimento dos sujeitos individuais, mas está limitado a uma gama específica de remédios, para usar a terminologia de Fraser.

5. O reconhecimento como auto-reconhecimento é essencial para a construção do sujeito da ação na luta social. Só existe o dominado contra a dominação se este se reconhecer como tal. Não há feminismo antes da feminista, assim como não há paridade participativa antes do sujeito auto-reconhecido como igual.

6. Tanto em Fraser como em Honneth há uma ausência de momentos de construção de situações de desrespeito, de não reconhecimento e de reconhecimento, o que limita o alcance de teorias. 
A divergência constituinte da polêmica organiza-se em torno do conceito de reconhecimento e a possibilidade de separá-lo ou não da noção de distribuição. Para Fraser, é possível pensar distribuição e reconhecimento de formas distintas, associando o primeiro ao material e o segundo, ao cultural, e "tratando ambos como uma questão de justiça social, isto é, como status social"; já Honneth não reconhece a possibilidade de o material expressar-se em si, mas através do simbólico, representado na luta por reconhecimento. É ao se auto-reconhecerem como sujeitos da falta, entendida aqui como desrespeito, que os indivíduos tornam possível sua luta por reconhecimento. A redistribuição neste cenário seria apenas uma forma de luta por reconhecimento. Fraser, de forma diversa, desenvolve uma teoria bidimensional, que engloba ambas as condições de forma igualitária. Trata, desta forma, de fazer um tipo de correção nas teorias contemporâneas que, segundo a autora, são excessivamente culturalistas, apontando que o pêndulo tende sempre para o reconhecimento e que as teses de Honneth são, segundo a autora, provas disto. Atribui tal tendência à centralidade do multiculturalismo e dos movimentos sociais identitários e da própria crise do chamado socialismo real. Afirma ainda que, em sua perspectiva, a redistribuição e o reconhecimento não são paradigmas filosóficos, mas paradigmas de justiça, que informam as lutas atuais na sociedade civil. Ela estabelece paradigmas populares para a distribuição e para o reconhecimento, atribuindo a cada um conjunto de acepções, que envolvem as causas e os remédios para a injustiça.

Em trabalho anterior (Fraser, 1997), Fraser fazia uma clara distinção entre injustiças, que tinham como causa a não distribuição, e injustiças que tinham como causas o não reconhecimento; agora fala de bidimensionalidade e pergunta se esta é uma exceção ou uma norma, para responder que todos os casos contêm distribuição e reconhecimento mesmo que com pesos diferentes. Contrapõe-se, desta for- 
ma, a Taylor e a Honneth, afirmando que para eles reconhecimento é reduzido à auto-realização e, especialmente para Honneth, o reconhecimento é o reconhecimento do outro, o que constitui uma questão filosófica e psicológica e não uma questão social dada fora dos sujeitos.

A distinção entre distribuição e reconhecimento mantida por Fraser necessita ser apropriada, tomando em consideração duas perspectivas: a primeira é a de pensar na "mádistribuição" dada pela posição dos agentes nas relações de produção, o que independe completamente do reconhecimento, tenha ele o estatuto que tiver. Aqui se está frente a uma característica estrutural do capitalismo. Uma segunda e diversa perspectiva é a forma de apropriação pelos agentes dessa situação de injustiça. Mesmo considerando que a injustiça não existe somente por força do auto-reconhecimento dos agentes, como sujeitos injustiçados, a bandeira de luta para a superação só emerge através da existência de 38 sujeitos subjetificados como injustiçados. O que estou apresentando não se trata da redução da questão social a um culturalismo radical, a respeito do qual Fraser acusa Honneth, em diferentes passagens da obra polêmica em pauta, mas de dois momentos distintos da questão. Voltarei a este ponto com mais detalhes, posteriormente.

Um tributo sempre pago a Fraser é que ela trouxe de volta para a discussão a questão da distribuição, que havia sido deixada de lado pelos filósofos multiculturalistas como Taylor (1994) e Kymlicka (1996) e, mesmo, por Honneth. Zurn, comentando Fraser afirma:

"Em muitos sentidos o trabalho de Nancy Fraser tem parecido seguir este modelo para desenvolver uma teoria crítica do reconhecimento. Uma importante distinção, entretanto, concerne a sua insistência na importância crucial da luta contra injustiças ancoradas em políticas econômicas da sociedade, especialmente, sua consideração 
de incontáveis caminhos em que estes problemas de má distribuição não são reduzíveis a, nem analisáveis dentro de um esquema das condições intersubjetivas do reconhecimento" (Zurn, 2003, p. 519).

Na questão específica do reconhecimento devem-se ter presentes dois processos bastante distintos: o primeiro refere-se ao reconhecimento para a superação, cujo caso clássico é a própria categoria de classe na teoria marxista; o segundo trata de uma questão muito diversa, que é a do reconhecimento como identidade. É neste segundo sentido que a perspectiva de Fraser parece encontrar um sério limite. Tome-se, por exemplo, um movimento social, como o movimento negro; nele, a noção de auto-reconhecimento é fundamental: não existe política que provoque mudança de status na condição do negro, se o negro não se reconhece como tal (como sujeito negro dominado). No Brasil, por exemplo, no que pese as leis anti-racistas serem bastante antigas, elas só começaram a ter alguma realidade como lei, quando os negros começaram a se reconhecer como sujeitos sobre os quais agia o preconceito.

Para Fraser, entretanto, parecem ser suficientes as leis anti-racistas, sem ser preciso considerar o sujeito que se auto-reconhece como discriminado. A autora afirma:

"Ver o reconhecimento como uma questão de justiça é tratálo como um caso de status social. Isto significa examinar padrões institucionalizados de valores culturais, pelos seus efeitos nos padrões relativos dos atores sociais. Quando estes padrões constituem atores como pares, capazes de participarem em condições de igualdade um com outro na vida social, então podemos falar de reconhecimento recíproco e igualdade de status. Quando, em contraste, padrões institucionalizados de valor cultural constituem alguns atores como inferiores, excluídos, totalmente outros, 
simplesmente invisíveis, isto é, menos que um parceiro completo na interação social, então nós falaremos de falso reconhecimento e status subordinado" (Fraser, 1997, p. 29).

Para enfrentar a questão, Fraser aponta para a necessidade de remédios que destitucionalizem" "padrões de valores culturais que impedem a paridade na participação”. Há uma reafirmação muito forte por parte da autora, ao longo da defesa de sua teoria, da idéia de subordinação, em contraposição à de igualdade, esta última representando a única forma de estabelecer justiça, sem entrar em avaliações de valores. Segundo ela,

"não há nenhuma concepção de auto-realização ou de boa
vida, que seja universalmente compartilhada, e nenhuma
pode ser estabelecida por autoridade" (Fraser, 1997, p. 29).

Ao mesmo tempo, Fraser afirma que sua base normativa é a noção de paridade de participação, definida como

"uma justiça que requer arranjos sociais que permitam todos os membros adultos da sociedade interagirem como pares" (Fraser, 1997, p. 29).

Para que isto aconteça, devem ser preenchidas duas condições: uma distribuição justa e o respeito a padrões culturais, duas noções que segundo a autora devem manter-se claramente distintas. Todavia, as questões de justiça social e de igualdade só se justificam como livres de intervenções valorativas se forem tomadas como tendo naturezas essenciais, o que não parece se adequar à postura teórica de

\footnotetext{
${ }^{2}$ A noção de desinstitucionalização em Fraser é bastante complexa, pois pressupõe o rompimento de identidades, que provocam o não-reconhecimento ou a mádistribuição. A noção está muito próxima de Marx quando este pensa na vitória do proletariado como sua própria extinção. Voltarei à questão em páginas adiante.
} 
Fraser. Se é razoável admitir que não existe uma natureza essencial para a igualdade e para justiça social, estas sofrem do mesmo problema da noção de "boa vida”. São todas elas condições negociadas através da história por embates sociais e variam com o tempo. Nenhum deles tem lugar privilegiado a partir do qual possa ser descrito.

Em decorrência disto, Fraser, quando chega ao nível analítico, cai em uma espécie de tautologia de difícil resolução, pois intui que, para a participação paritária existir, é preciso haver como ponto de partida uma justiça democrática, "que deve perseguir a adoção da deliberação dos cidadãos sobre o que é melhor para implementar a justiça”. Tal objetivo pode ser atingido, segundo a autora, por afirmação (transferência de renda, valorização de grupos desvalorizados), ou por transformação, que resultaria no socialismo, destituindo identidades. Fraser, ao substituir valores por justiça, não resolve o problema que ela própria aponta em Honneth, pois aqui também está implícita uma decisão anterior à paridade, ou seja, anterior à justiça. Se é a justiça democrática que levará à participação paritária, conseqüência da distribuição e do reconhecimento, que cidadãos são estes que a definirão?

O conceito de participação paritária em Fraser indica a existência de uma sociedade justa, mas aí reside um sério limitador: se a participação paritária for apenas o cumprimento dos princípios liberais acordados nos pactos constitucionais das democracias modernas, o conceito é fraco e tem pouco valor explicativo ou normativo; se, de forma distinta, representar um novo tipo de acordo, ele carece de agentes capazes de levá-lo a bom termo.

Fraser indica dois pressupostos para que a participação paritária ocorra: a remoção de obstáculo para uma participação social completa e o desmantelamento dos obstáculos culturais institucionalizados. A pergunta que se impõe é: como realizar isto? A resposta é problemática, devido 
aos próprios limites que a autora impõe à amplitude da transformação; na sua fase mais recente, Fraser abandona a "transformação", que viria a ser a negação da diferença, para trabalhar no limite da democracia liberal de inspiração capitalista. Tal escolha lhe possibilita uma posição de maior intervenção na ação social, mas retira do aporte teórico a amplitude para tratar com os sujeitos envolvidos na ação. Fraser faz uma mudança teórica sutil, mas importante: deixou de falar a partir de sujeitos, para falar a partir da institucionalização dos direitos.

Honneth critica Fraser por pensar separadamente o material e o simbólico, e constrói um elo entre eles. Opõe-se à centralidade dos movimentos sociais como indicadores de conceitos normativos para a teoria crítica e chama atenção para a necessidade de desmistificar a luta pelas identidades dos movimentos sociais, pois apenas um pequeno número encontra reconhecimento nela. Para enfrentar estas ques-

42 tões, Honneth propõe uma "teoria do reconhecimento suficientemente diferenciada", tratando a distribuição como decorrência do reconhecimento. Em suas palavras:

"a formulação conceitual do reconhecimento é de central importância hoje, não porque expressa os objetivos de um novo tipo de movimento social, mas porque ela tem provado ser uma ferramenta apropriada para categorialmente desvendar experiências sociais de injustiça como um todo" (Honneth, 2003, p. 133).

Honneth associa a injustiça à percepção de injustiça e afirma que as lutas proletárias sempre estiveram associadas à identificação de injustiça como desrespeito. Desta forma, não seria possível isolar as lutas por reconhecimentos das lutas por redistribuição. A imbricação destes dois princípios seria uma necessidade do próprio capitalismo, que: 
"necessita de uma legitimação racional através de um princípio generalizável de reconhecimento. Sua reprodução permanece dependente na base de um consenso moral" (Honneth, 2003, p. 152).

A crítica a Honneth quanto à redução do reconhecimento a um culturalismo clássico do tipo Taylor, entretanto, não parece totalmente correta pois, diferentemente dos culturalistas, Honneth não está pensando no reconhecimento como constituição de diferença , mas como uma forma de luta que substituiria a luta de classes e outras lutas por distribuição. Honneth vê o reconhecimento como a forma através da qual os sujeitos vivenciam situações de injustiça. Em seu embate com Fraser, percebe-se, claramente, a distância que busca estabelecer em relação a posturas próximas ao multiculturalismo:

"Não é o particular, deixado sozinho agora, idéia central de coletivos oprimidos - sejam estes caracterizados em termos de 'diferença' ou 'reconhecimento cultural' - que agora estão a prover a base para um enquadramento normativo da teoria do reconhecimento. Ao contrário, o que deu impulso - realmente impulsionou - esta revisão categorial foram os achados que têm sido compilados no que concerne aos recursos morais da experiência, do descontentamento social" (Honneth, 2003, p. 133).

A questão do reconhecimento colocada pelos dois autores tem uma distinção que é fundamental para o entendimento da própria controvérsia em que se colocam. Fraser pode distinguir o reconhecimento da distribuição porque não associa tais noções a atores, mas a princípios de justiça e a remédios, isto é, a políticas públicas ${ }^{3}$. Honneth, de for-

\footnotetext{
${ }^{3}$ Na verdade, os textos de Fraser deixam completamente de fora as ações institucionais que tornariam possíveis a concretização do que chama de remédios, posição que divide com grande parte dos pensadores do multiculturalismo e mesmo
} 
ma diversa, parte de uma ação do ator que se autodefine como objeto do reconhecimento. Esta ação exige a presença do outro; trata-se, pois, de uma relação. Apesar de Fraser ter um pensamento mais militante e propor remédios (ações concretas), a noção de conflito está mais presente em Honneth, como se pode observar em seu conceito de luta social:

"processo prático no qual as experiências individuais de desrespeito são interpretadas como experiências cruciais típicas de um grupo inteiro, de forma que elas podem influir como motivos da ação, na exigência coletiva para relações ampliadas de reconhecimento" (2003, p. 138).

Vale aqui fazer um parêntese para examinar a questão do reconhecimento a partir de dois casos completamente distintos e que têm particular importância na discussão 44 que estamos levando a efeito: o movimento dos sem-teto e o movimento negro. O primeiro reconhece sua condição para se organizar e lutar a fim de superar a condição de pobreza, de falta de trabalho e educação: sua luta se dá pela superação das condições do reconhecimento, isto é, pela desconstrução da própria condição. O segundo organiza-se também para superar suas condições de pobreza, trabalho e educação, mas no sentido de reforçar sua cultura, sua história própria, seus valores religiosos, buscando direitos especiais, quando for o caso. Há, portanto, uma grande diferença entre estes fenômenos, que terão conseqüências muito distintas.

daqueles que trabalham com a teoria da democracia, com ênfase na participação da sociedade civil, o que parece tirar deles um instrumento importante de análise. Estou introduzindo neste texto a noção de política pública por parecer-me ser esta a única possibilidade de levar a cabo a proposta de Fraser. Exceção aos autores é Íris Young em seu último e definitivo livro Inclusion and democracy (2000), em que acentua a importância do papel do Estado em políticas de inclusão (reconhecimento). 
Para explicar o surgimento e a luta destes movimentos, o conceito de reconhecimento necessita enfrentar a questão da identidade e, principalmente, da constituição do sujeito de luta. E neste momento o reconhecimento não é apenas uma questão de justiça social, mas de auto-reconhecimento, de auto-estima e de luta pelo reconhecimento do outro.

A noção de reconhecimento em Honneth é aqui, particularmente, importante. Ele enfatiza a ordem institucionalizada no sistema capitalista através de três momentos: o reconhecimento privado da pessoa através do amor, isto é, do casamento burguês; o reconhecimento legal, através do sistema de leis; e o reconhecimento ideológico, através das realizações pessoais que, segundo o autor, têm como ponto de partida um homem de classe média. Para Honneth, "as realizações pessoais são um recurso normativo da burguesia para justificar a distribuição extremamente desigual”. Dentro deste quadro, Honneth reafirma que não é possível separar o material do cultural no capitalismo, pela necessidade, já apontada, de um consenso moral.

No Brasil, as noções de distribuição e reconhecimento foram tradicionalmente tratadas como sendo duas questões distintas. A noção de distribuição tem muito mais tradição do que a de reconhecimento; tem sido o espaço privilegiado de teses de economistas, que se preocupam com a desigualdade social, identificada como sinônimo de concentração de renda. Tal identificação também tem sido recorrente nos discursos governamentais de todos os matizes ideológicos. Toda a discussão sobre a renda mínima está dentro deste espectro $^{4}$. Não se trata aqui de negar esta identificação, por óbvia. Mas de chamar a atenção para o fato de que a simples distribuição não pode ser vista como a panacéia para o problema de desigualdade, pois esta tem raízes bastante varia-

\footnotetext{
${ }^{4}$ No Google Acadêmico, existem em português e em relação ao Brasil 23.900 citações para "distribuição de renda"; 12.000 para "renda mínima"; 1.230 para política compensatória; 830 para "ações afirmativas e 300 para "políticas de cotas".
} 
das. A noção de reconhecimento foi introduzida no país junto com as discussões sobre a diferença, bastante próxima das questões feministas e as dos movimentos gays, e está embebida de idéias pós-estruturalistas inspiradas em Derrida, Lacan, e em feministas como Lucy Yrigaray, Judith Buttler, Chantal Mouffe e Julia Kristeva. Posteriormente, diferença e reconhecimento tornam-se uma questão de justiça social, principalmente através do movimento negro e de sociólogos que trabalham com o tema ${ }^{5}$. Pobreza e negritude formaram um binômio quase sinônimo de distribuição e reconhecimento. A discussão atual no Brasil sobre políticas de ações afirmativas para alunos de escolas públicas e para afro-descendentes nas universidades públicas vem muito informada pela manutenção dessas duas noções. Interessante observar, nas duas políticas, que a primeira tende a ser mais aceita pelo establishment acadêmico, enquanto a segunda é arduamente defendida pelo movimento social. Tal postura parece estar 46 calcada em um conjunto de características culturais e políticas. De caráter cultural, a não aceitação das cotas raciais está diretamente associada à idéia, vastamente difundida no Brasil, da democracia racial, em contraste com o regime de segregação adotado em época passada nos Estados Unidos. De ordem política, há uma vertente ideologicamente bastante distinta, na medida em que a negação da funcionalidade das cotas está associada à negação da classe como unidade única e legítima de luta. Como decorrência, há uma maior aceitação das ações afirmativas dirigidas aos setores mais pobres, que em princípio pertenceriam ao proletariado.

Esta constatação pode ser um bom caminho para levar adiante a questão central deste artigo, que é o sentido da polêmica entre Fraser e Honneth, em cenários diferentes dos que lhe deram origem. Cabe neste momento levantar

\footnotetext{
${ }^{5}$ Entre os autores que trabalham com o tema no Brasil podemos citar Antonio Sergio Guimarães (2006); Edward Telles (2003); José Jorge de Carvalho (2005).
} 
alguns pontos que marcam a distinção entre os dois cenários: primeiro, a situação do Estado de bem-estar social de que partem Fraser e Honneth, para discutirem as noções de distribuição e reconhecimento, determina em quaisquer dos casos a forma como as duas noções se relacionam. $\mathrm{Na}$ Europa e nos Estados Unidos, uma longa história do Estado de bem-estar social e de riqueza econômica condiciona a forma como as questões de distribuição e reconhecimento são pensadas. A primeira tendeu a ser quase um caso residual, na medida em que a grande maioria das populações esteve protegida da miséria, da fome e da pobreza em geral. A segunda questão aparece, fortemente, a partir do crescimento dos novos movimentos sociais, principalmente de feministas, negros e de gays e lésbicas. Daí que nesses cenários a luta por constituição de identidade e reconhecimento é muito presente, mesmo quando a questão é distribuição. O caso do Brasil, onde há um seríssimo déficit de bem-estar social, grandes parcelas da população estão fora da possibilidade de constituírem-se como sujeito de luta por distribuição e reconhecimento, sejam estes entendidos como status ou auto-reconhecimento. O segundo ponto a considerar é que, tomando tal realidade em consideração, existirá sempre uma política de distribuição (ou não) e uma política de reconhecimento (ou não), que independe do sujeito individual ou do grupo social. Os pobres na América Latina, ou a massa de miseráveis no mundo, estão muito mais expostos a sofrerem ações de alguém, que distribui ou que lhes reconheçam, do que serem sujeitos do auto-reconhecimento.

A distribuição, quando está associada a padrões de extrema pobreza, é um remédio que não envolve qualquer tipo de processo de auto-reconhecimento. Políticas de renda mínima, de cestas básicas, ou a distribuição de salário mínimo para toda a população, não envolvem demandas ou auto-reconhecimento; são políticas de governo de centroesquerda, mais afetos à questão social, ou correspondem a 
uma fase do capitalismo, que já não necessita deixar populações vivendo abaixo do nível da miséria para se reproduzir; ou ainda, são decorrentes de políticas de cooperação internacional, via ONU ou ONGs.

A polêmica Fraser-Honneth toma uma direção diversa em cenários de grande pobreza e desigualdade social, na medida em que a noção de reconhecimento fica mais limitada a um reconhecimento externo; isto é, o outro reconhece e age sem necessariamente construir uma relação com o reconhecido, como ocorre no processo de auto-reconhecimento na teoria de Honneth. O outro, no caso, é sempre ou quase sempre um agente estatal que atua através de políticas públicas. Tanto nas teses de Fraser, como nas de Honneth, há um elo perdido entre o reconhecimento e a redistribuição e o sujeito sobre o qual estas ações operam. O fato de Honneth ver o reconhecimento como o reconhecimento do outro não resolve a questão, porque podemos estar

48 frente a uma situação em que o outro reconhece a falta, sem que o reconhecido se reconheça. O elo perdido parece ser o processo de construção de discurso, ou apropriação de elementos discursivos (que Fraser chama de paradigmas populares), por parte daqueles excluídos sociais, para que no espaço público eles possam constituir-se como o promotor da ação social a partir de sua própria construção como agente, concomitante às demandas e ao aparecimento de espaços e possibilidades políticas de reconhecimento. Sem este processo, é impossível entender tanto a paridade participativa de Fraser como o auto-reconhecimento e a percepção de desrespeito em Honneth.

Em relação às questões até aqui apresentadas, é mister discutir a presença do Estado como um elemento importante: tanto nos países geradores das reflexões de Fraser e Honneth, como no próprio caso do Brasil, trata-se de cenários com Estados nacionais enraizados e campos políticos bem definidos, principalmente nos países do hemisfério norte. 
Isto pressupõe uma história incorporada de lutas por direito e de pluralidade de discursos que incorporam questões de distribuição e reconhecimento. Os limites do Estado têm sido muito fortemente estudados, principalmente por teóricos que vêem a sociedade civil como o espaço privilegiado da vida pública. Mesmo admitindo que o Estado tem grandes dificuldades e o espaço político está em alguns casos bastante contaminado por uma incapacidade de resposta do Estado aos grandes problemas, a existência de tal espaço não pode deixar de ser considerada nos discursos políticos, que constituem o cidadão e o ente público. O reconhecimento ou o não reconhecimento, a distribuição ou a concentração de renda são alicerces de discursos políticos, que entram em embate com diferentes soluções e, desta forma, chegam ao poder público institucional, isto é, ao Estado.

Tendo as questões acima apontadas em mente, as duas propostas trazem contribuições importantes para que se pense cenários como o brasileiro e também para quebrar barreiras, tanto de uma tradição economicista como a de um certo modismo culturalista. Como foi afirmado anteriormente, em cenários como o do Brasil, a polêmica Fraser-Honneth perde parte de seu sentido, uma vez que se pode admitir, ao mesmo tempo, questões de distribuição exclusivas e questões em que o tema da distribuição só pode ser pensado como luta por reconhecimento. No primeiro caso, estou pensando em distribuição como remédio; no segundo, como luta por conquista de direitos. Neste particular parecem estar os dois maiores limites dos dois autores: Fraser não definir o que são as políticas públicas, isto é, os remédios de distribuição e reconhecimento; e Honneth não esclarecer o que são as lutas e como é possível novas formas de reconhecimento. A noção de remédios para os dois diferentes males, identificados por Fraser, não recebe da autora um aprofundamento maior; por exemplo, quem decidiria os tipos de intervenção (remédios)? Quem estaria 
habilitado a receber estes remédios? E o que é mais importante: quem é o executor dessa política?

A questão do Estado e do político aqui é fundamental, pois não há possibilidade de justiça social ou paridade participativa sem uma instância que possa intervir, a partir de um regramento universal. Avritzer (2007) enfatiza esta questão, atribuindo à última um compromisso com o tema, não encontrado em Honneth. Na verdade, a presença do Estado e do político está muito mais clara no texto de Avritzer $^{6}$ do que em Fraser, que mantém sempre uma discreta distância em relação ao próprio Estado liberal capitalista, dentro do qual localiza suas análises e propostas.

Se o Estado, tal qual está proposto, é o responsável por grande parte das injustiças, este mesmo Estado só pode ser o executor das tarefas a ele atribuídas por Avritzer e Fraser, se for transformado em agente de políticas socialmente justas. Para escapar a uma espécie de tautologia, é neces50 sário incluir no circuito um elemento de fora, que passa a não deixar que o Estado reproduza a injustiça; e aqui pode tratar-se de grupos identitários, movimentos sociais, ou simplesmente a sociedade civil. É no embate entre o sistema e seus elementos exteriores que se poderá reconstituir o Estado. E nesta inflexão temos de trazer de volta o sujeito autoreconhecido como o detentor de direitos, que enfrenta politicamente o Estado. Tal proposição não pode ser entendida, evidentemente, como um Estado de coisas constantemente verificável no nível empírico. Há situações onde a ação do Estado dirige-se a populações sem nenhum processo prévio

\footnotetext{
${ }^{6}$ Avritzer, em seu importante texto sobre a polêmica Fraser-Honneth - "Do Reconhecimento do self a uma política institucional de reconhecimento: uma abordagem da polêmica entre Axel Honneth e Nancy Fraser" (2007) -, enfatiza o caráter político-legal do reconhecimento como fundamental e encontrado nas posturas teóricas de Fraser. Sem dúvida, não há como discordar de Avritzer que o reconhecimento deve ser "implantado definitivamente na arena legal". Todavia minha discordância está na defesa do abandono do self; sem ele me parece bastante difícil construir um cenário de inclusão cidadã, que supere políticas paliativas.
} 
de auto-reconhecimento, como é caso de algumas políticas distributivas.

\section{Duas questões muito brasileiras}

Na parte final deste texto, gostaria de analisar as possibilidades heurística e normativa das teses de Fraser e Honneth, considerando dois temas muito ligados à realidade brasileira: a política de ações afirmativas para afro-descendentes e a desigualdade constitutiva da cidadania.

O Brasil tem 32,9\% da população considerada pobre e $13,5 \%$ vivendo em extrema pobreza; isso significa aproximadamente 22 milhões de pessoas. Um recente estudo sobre as características da pobreza no Brasil, realizado pelo Banco Interamericano de Desenvolvimento e assinado por Herran, associa os dados da pobreza aos da desigualdade social, afirmando que a primeira tem mais a ver com a desigualdade do que com o crescimento econômico. No país, $1 \%$ dos mais ricos detêm $10 \%$ da renda bruta; e este mesmo percentual representa a riqueza dos $50 \%$ mais pobres. Portanto, a primeira constatação que se retira destes dados é a de que há necessidade premente de políticas de distribuição, que atinjam universalmente os pobres. Quando busca caracterizar a pobreza, Herran (2005) mostra que ela atinge de forma diversa diferentes grupos:

"Famílias com crianças (de 0 a 6 anos), ou famílias chefiadas por afro-descendentes ou indígenas, respondem por dois terços do total de famílias pobres. Domicílios no nordeste respondem pela metade de todas as famílias pobres, e famílias cujo chefe tem menos de quatro anos de escolaridade respondem por $54 \%$ da pobreza familiar" (Herran, 2005, p. 34).

Aqui novamente temos um problema de reconhecimento, que foge à noção de Honneth, pois criar políticas 
compensatórias por grupos específicos para retirá-los da situação de pobreza extrema é uma decisão política que envolve reconhecimento, no sentido explícito de Fraser. Neste caso, o reconhecimento está completamente dissociado da identidade auto-constituída, pois ele é um reconhecimento a partir do Estado. Ao contrário, tal reconhecimento pretende superar a condição que está sendo reconhecida, permitindo seu desaparecimento como diferença significativa. Na solução socialista para a questão da distribuição e reconhecimento, Fraser aponta a dissolução dos traços que tornam o sujeito reconhecido como a solução; essa questão, entretanto, tem sérios complicadores quando encontra grupos que lutam pela diferença e pelas características específicas daquela diferença, e que têm uma história acumulada. Um exemplo é o das comunidades quilombolas no Brasil.

Em relação à política de ações afirmativas, é interessante contrastar as teses de Avritzer e Feres, na medida em 52 que estes partem dos dois autores aqui discutidos para chegarem a conclusões bastante distintas. Avritzer defende as ações afirmativas para afro-descendentes a partir da noção de reconhecimento como status:

“Apenas uma concepção política pode levar à constituição de um novo status cujo elemento principal precisa ser o reconhecimento pela totalidade da comunidade política de uma falha na sua concepção de justiça. A correção desta falha que pode surgir ou do diálogo ou da luta social deve corresponder a novos direitos cuja institucionalização política é condição sine qua non para a sua vigência. Em um momento no qual países como o Brasil, a África do Sul e a Índia passam a implementar políticas afirmativas que buscam reparar danos causados por uma dominação perversa tanto privada quanto estatal, é fundamental que o reconhecimento abandone o campo do self e se implante definitivamente na arena política legal" (Avritzer, 2007, p. 8) 
De forma diversa, Feres, ao analisar a teoria do reconhecimento, aponta para o perigo de este ocorrer pela reafirmação da posição assimétrica racial. Em relação à questão de reconhecimento posta por Honneth, Feres afirma:

"[...] através desse instrumental analítico, a pessoa, ou grupo de pessoas, pode localizar e rejeitar formas lingüísticas que lhe atribuam um caráter de imaturidade, primitivismo ou inferioridade, sem ter que assumir publicamente qualquer identidade específica” (2002, p. 8).

Para concluir, no que concerne às ações afirmativas:

"Por exemplo, nos EUA, programas como affirmative action e outros benefícios proporcionam incentivos àqueles que se identificam como minorias. Contudo, ao se identificar publicamente dessa maneira, a pessoa está explicitamente assumindo o caráter subalterno de sua posição. Isto leva a uma contradição prática na qual, para se tornar igual, a pessoa deve apresentar-se como inferior. Resta-nos saber se esse tipo de programa é capaz de superar essa contradição" (Feres, 2002, p. 8).

Minha posição em relação às duas posturas reforça as hipóteses que levantei inicialmente neste artigo. Concordo com ambas as posições, mas apenas parcialmente. É certo que, como afirma Avritzer, as políticas de ação afirmativas para afro-descendentes decorram da necessidade de superar injustiças através de intervenção política (rearticulação de status). Porém, não se pode esquecer que em todos os lugares em que aconteceu, tal processo foi, primordialmente, decorrência da mobilização de sujeitos que se auto-reconheceram como negros e como detentores de direitos a eles devidos. E é esta condição de emergência que possibilita a construção de um cenário para a participação paritária. 
Feres, por seu turno, parece pintar com cores muito fortes os perigos do auto-reconhecimento, atribuindo a ele, necessariamente, uma posição de subalternidade.

A questão das políticas de ações afirmativas voltadas a grupos étnicos no Brasil, no caso dos afro-descendentes, é bastante complexa e tem dividido intelectuais e o próprio movimento negro. A controversa questão no Brasil, que resultou em políticas de ações afirmativas em um considerável número de universidades públicas, cumpriu uma trajetória histórica importante de ser aqui considerada. Em um primeiro momento, identifica-se a existência da questão de forma generalizada nas discussões sobre direitos, a partir da década de 1960 no ocidente; posteriormente, com o processo de democratização no Brasil, durante a década de 1980, e com a Constituição de 1988, a questão dos direitos tornou-se central nos debates públicos. Esta circulação de idéias e posições pode ser identificada com o que Fraser 54 chama de paradigmas populares.

O próximo momento neste processo foi o da constituição do negro, no interior ou não do movimento negro, como uma identidade positiva, valorizando seu visual, sua estética, sua cultura e principalmente sua história. Este é o momento de auto-reconhecimento. É mister chamar a atenção para o fato de que não se trata de um reconhecimento de desrespeito em relação a uma situação anterior, o que parece ser o grande limite da Honneth, e que levaria a uma situação onde a inovação não seria possível, como muito bem observa Feres . Completa o processo o momento político institucional de implantação da política apontado por Avritzer, no artigo antes citado.

A questão que gostaria de enfatizar neste momento é a da constituição do sujeito como portador de auto-reconhecimento, como condição necessária do processo. Não se está tratando aqui de defender a indefensável posição de que o processo só ocorre se houver um trabalho de auto- 
reconhecimento de massas. No entanto, é necessário atentar para o fato de que a ação compensatória não depende de que todos os negros, no caso, tenham se constituído como sujeitos em luta; entretanto, quando esta ação não é automática, ou seja, quando há necessidade de uma autodeclaração para que o indivíduo seja incorporado, a presença do auto-reconhecimento é fundamental. No caso específico das cotas para afro-descendentes nas universidades a autodeclaração é, pela própria natureza da política, uma exigência. Aquele negro que, por razão qualquer, não se reconhece como tal, não assinará um documento declarando-se negro.

O segundo exemplo sobre o qual gostaria de tecer algumas considerações à luz das teses desenvolvidas por Fraser e Honneth refere-se à desigualdade cidadã, não como um arcaísmo, mas como algo constitutivo do capitalismo moderno brasileiro. Não é o caso aqui de desigualdade social tal como foi apontado anteriormente, mas do não reconhecimento da igualdade perante a lei, tanto das camadas superiores da população como das camadas mais pobres. Todos se auto-identificam como desiguais.

José Murillo de Carvalho, ao comentar a frase clássica da elite brasileira "Você sabe com quem está falando?", descreve com muita propriedade esse hibridismo nacional:

"Quantos guardas de trânsito, quantos policiais, quantos fiscais, quantos funcionários de repartição pública, quantos empregados de hotéis, lojas, aeroportos, cinemas, quantos cidadãos comuns já não ouviram esta frase dita por quem se considera socialmente superior pela riqueza, pelo poder, pela educação, pela cor da pele, pelos laços familiares ou por simples presunção e arrogância? Com o 'você sabe' o superior tenta impor sua vontade reafirmando a hierarquia social à e por cima da lei” (Carvalho, 1998, p. 322). 
As observações de Carvalho dão concretude à questão que estou tratando de desenvolver. Cada brasileiro não se vê como igual ao conjunto da população, ou porque é elite e não admite ter só os mesmos direitos de todos, ou porque a grande maioria e principalmente os pobres, os $30 \%$ de que falávamos acima, não se sentem cidadãos portadores de direitos. Daí que os serviços que o Estado deveria prestar com eficiência muitas vezes são vistos como favores, o que oferece uma grande margem para corrupção e construção de relações clientelistas, por parte dos políticos do País.

A noção de reconhecimento como status, contida nas teses de Fraser, está muito informada pela idéia de cidadania. A paridade de participação pode ser entendida como um princípio de igualdade entre todos os participantes. Tomando o caso do Brasil, ilustrado por Carvalho, a questão no País pode ser muito bem explicada por Fraser e os remédios de que ela fala, os quais poderiam aqui fazer

56 bons efeitos. Como Fraser omite-se na maioria das vezes de indicar a receita destes remédios, a pergunta que se faz é: quando se trata de direitos e não simples distribuição, como chegar à igualdade participatória, se os cidadãos não se reconhecem como iguais? Nesta circunstância, a questão do auto-reconhecimento parece fundamental, na medida em que as camadas despossuídas de direitos se auto-constituírem como carentes pela presença de um outro, por sua vez, constituído por muitos direitos. Essa espécie de dialética permitiria chegar a uma situação de igualdade. Neste exemplo, ficam claros as possibilidades e os limites da posição de Fraser, bem como a possibilidade de se pensar uma ação complementar das duas noções de reconhecimento, em cenários completamente distintos dos que geraram as teses.

\section{À guisa de conclusão}

$\mathrm{Na}$ introdução deste artigo levantei seis pontos a propósito dos conceitos de distribuição e reconhecimento, como 
hipóteses para discutir a polêmica Fraser-Honneth. Ao longo do texto, tratei de discutir cada um destes pontos, e nas páginas finais discuti as duas noções com o foco em questões brasileiras. Neste momento, gostaria de encerrar, retomando de forma geral os pontos antes mencionados, para reforçar a hipótese principal de que há complementaridade entre as duas propostas e de que, para a avaliação de situações brasileiras, abandonar uma proposta em favor de outra empobreceria as qualidades heurísticas e normativas, que podem ser encontradas na combinação das duas.

Tal procedimento é fundamental no meu entendimento, pois possibilita a não redução da distribuição ao reconhecimento e, ao mesmo tempo, não limita o reconhecimento ao auto-reconhecimento (auto-estima) ou à política de status. Esta abertura permite o entendimento da complexidade de cenários em embates, tanto no interior da sociedade, como nas políticas públicas, suas aplicações e limites.

Finalmente, é mister chamar a atenção para o fato de que ambas as teorias carecem de mostrar os procedimentos de construção dos processos pelos quais os agentes sociais e/ou estatais se encontram envolvidos em certos momentos históricos, em lutas e ações de distribuição e reconhecimento.

\section{Celi Regina Jardim Pinto}

é professora do Departamento de História e do Programa de Pós-graduação em História da UFRGS

\section{Bibliografia}

AVRITZER, L. 2007. "Do reconhecimento do self a uma política institucional de reconhecimento: uma abordagem da polêmica entre Axel Honneth e Nancy Fraser”. Anpocs 2007 ST Teoria Social. CD-ROM.

BENHABIB, S, 2002. The claims of culture - Equality and diversity in the global era. Princeton: Princeton University Press.

CARVALHO, J. J. de. 2005. Inclusão étnica e racial no Brasil - A questão das cotas no Ensino Superior. São Paulo: Attar Editorial.

CARVAlHO, J. M. de. 1998. Ponto e bordados - Escritos e bordados. Belo 
Horizonte: Ed. UFMG.

FERES JR., J. 2002. "Contribuição a uma topologia das formas de desrespeito: para além do modelo hegeliano-republicano". Dados, Rio de Janeiro, vol. $45, \mathrm{n}^{\circ} 4$.

FRASER, N. 1995. "Anttitheses". In: NICHOLSON, L. Feminist contentions. A philosophical exchange. London: Routledge.

1997. Justice interruptus critical reflection on the "postsocialist" condition. New York: Routledge.

; HONNETH, A. 2003. Redistribution or recognition? A politicalphilosophical exchange. London: Verso.

GUIMARÃES, A. S. A. 2006. "Depois da democracia racial". Tempo Social - Revista de Sociologia da USP, São Paulo: USP, vol. 18, pp. 269-290.

HERRAN, C. A. 2005. Reduzindo a pobreza e a desigualdade no Brasil. Rio de Janeiro: BID-Ipea.

HONNETH, A. 2003. Luta por reconhecimento - A gramática moral dos conflitos sociais. São Paulo: Editora 34.

KYMLICKA, W. 1996. Multicultural citizenship: a liberal theory of minority rights. Oxford: Oxford University Press.

LACLAU, E. 1994. The making of political identities. London: Verso.

58 Princeton: Princeton University Press.

TELLES, E. 2003. Racismo à brasileira. Rio de Janeiro: Relume Dumará.

YOUNG, I. M. 2000. Inclusion and democracy. Oxford: Oxford University Press.

WALZER, M. 1990. Spheres of justice: a defense of pluralism and equality. New York: Basic Books.

ZURN, Christopher. 2003. Constellation. London, vol. 10, $\mathrm{n}^{\circ} 4$. 


\section{NOTA SOBRE A CONTROVÉRSIA FRASER-HONNETH INFORMADA PELO CENÁRIO BRASILEIRO}

CELI REGINA JARDIM PINTO

O artigo examina a controvérsia Honneth-Fraser (2003) a propósito do binômio distribuição-reconhecimento e do estatuto teórico do conceito de reconhecimento, com o objetivo primeiro de discutir a aplicabilidade das propostas para casos como o brasileiro: até onde Honneth e Fraser oferecem instrumentos para análise do Brasil, até onde suas teorias têm valor normativo para o país? O texto está estruturado em duas partes: na primeira, analisa a polêmica em si e, na segunda, trabalha com as noções de 
distribuição e reconhecimento com base no cenário brasileiro contemporâneo.

Palavras-chave: Nancy Fraser e Axel Honneth; Distribuição; Reconhecimento; Brasil.

\section{A NOTE ON THE FRASER-HONNETH CONTROVERSY: THE BRAZILIAN CONTEXT}

This article examines the Fraser-Honnenth controversy (2003) in relation to the distribution-recognitions binominal and the theoretic status of the concept of recognition, with the aim to discuss the applicability of their proposals to cases as the Brazilian one. Do those theories have normative value to the country? The article has two parts: the first one analyzes the controversy in itself; the second part discusses the theses as far as the contemporary Brazilian scenario is concerned.

Keywords: Nancy Fraser and Axel Honneth; Distribution; Recognition; Brazil. 